\title{
A SIMPLIFIED METHOD FOR THE DETERMINATION OF THE BLASTOMERE NUMBERS IN PREIMPLANTATION RABBIT BLASTOCYSTS*
}

\author{
SEIIGHIRO FUJIMOTO, NAHID PAHLAVAN AND W. R. DUKELOW \\ Endocrine Research Unit, Michigan State University, \\ East Lansing, Michigan 48823, U.S.A.
}

(Received 5th March 1973)

Current literature indicates that chromosomal imbalance is causally related to some developmental anomalies and wastages in utero. While the incidence of gross chromosomal abnormalities in the human newborn population is estimated to be $0.5 \%$ (Lubs \& Ruddle, 1970), much higher incidences have been reported in spontaneous and threatened abortions (Carr, 1965; Geneva Conference, 1966; Makino, Ikeuchi, Sasaki, Muramoto, Shimba, Fujimoto \& Matsuda, 1967; Ikeuchi, Sasaki, Kohno, Hayata \& Fujimoto, 1972).

On the other hand, it has been observed experimentally, on the basis of differences between the numbers of CL and conceptuses, that early embryonic wastage is a common phenomenon in some laboratory mammals (Falconer, 1960; Ohzu \& Makino, 1964). Some workers (Ford \& Woollam, 1963; Shaver \& Carr, 1967; Kinsey, 1967; Hansen-Melander \& Melander, 1971) have described techniques to stain blastocyst cells of rabbits for chromosomal analysis.

Recently, in rabbits, Hansen-Melander \& Melander (1971) reported on three cases of chromosomally abnormal, small blastocysts, and Widmeyer \& Shaver (1972) found that oestradiol, especially when administered $1 \mathrm{hr}$ after mating, caused a significant increase in chromosomally abnormal blastocysts with a reduction in size. They reported that many of the smaller blastocysts receiving oestradiol could not be chromosomally analysed.

Although both the histo-morphological approach to the study of early-stage conceptuses, and the cytogenetic method have been widely and routinely utilized, neither appears to satisfy the requirements of future experimental teratology and embryology. Measurement of the numbers of blastomeres and cells in mitosis appears to be more helpful in assessing the developmental normality or abnormality of the blastocysts. The present communication reports a simplified method for the determination of the number of blastomeres and the mitotic indices in the preimplantation rabbit blastocyst at 4 to 6 days of pregnancy.

Mature female rabbits of mixed breeds were mated to fertile males following induction of ovulation by injection of 100 i.u. PMSG, intramuscularly (Lilly Laboratories) 4 days before mating and 100 i.u. HCG intravenously (A.P.L.,

* Michigan Agricultural Experiment Station Journal Article No. 6306. 
Ayerst Laboratories) immediately after mating. This results in ovulation approximately $10 \mathrm{hr}$ later (Harper, 1963). Chromosomally normal females and males were used for this study. All does were caged separately for at least 4 weeks before mating to preclude pseudopregnancy. The does were killed with an overdose of sodium pentobarbitone 4,5 or 6 days after ovulation and the uterine horns were carefully flushed with saline warmed to $37^{\circ} \mathrm{C}$ for the recovery of intact blastocysts. The number of CL was recorded.

The blastocysts were immediately washed in prewarmed TC 199 and the equatorial (long) and polar (short) diameters were determined by means of a filar micrometer eyepiece mounted on a dissecting microscope. As soon as possible after measurement, the blastocysts were placed intact in fresh culture medium (TC 199), to which colchicine had been added at the final concentration of $0.5 \mu \mathrm{g} / \mathrm{ml}$, and incubated, with loosened covers, in an atmosphere of $5 \% \mathrm{CO}_{2}$ in air at $37^{\circ} \mathrm{C}$ for $1 \frac{1}{2} \mathrm{hr}$. Each blastocyst was then transferred into $5 \mathrm{ml} 0.9 \%$ sodium citrate solution contained in a siliconized centrifuge tube. After $10 \mathrm{~min}$ at room temperature, centrifugation was carried out at 800 $\mathrm{rev} / \mathrm{min}$ for $5 \mathrm{~min}$. The supernatant was replaced with $5 \mathrm{ml}$ of a fixative solution consisting of methyl alcohol and glacial acetic acid $(3: 1)$. The preparations were then stored with parafilm seals for $24 \mathrm{hr}$ at $4^{\circ} \mathrm{C}$.

After subsequent centrifugation, $4.5 \mathrm{ml}$ of the supernatant fixative was discarded and the remaining $0.5 \mathrm{ml}$ made up to a total volume of $10 \mathrm{ml}$ with $45 \%$ acetic acid. The cells were homogeneously resuspended in this volume. Next, $0.5 \mathrm{ml}$ of this cell suspension was dropped gently onto a glass slide, warmed to 50 to $56^{\circ} \mathrm{C}$. Usually, several replications of the same preparation were made.

After drying, the slides were dipped into ethanol and stained with ammoniacal Giemsa for $5 \mathrm{~min}$.

The rest of the cell suspension in $45 \%$ acetic acid was recentrifuged and stained for later chromosomal analysis.

All the centrifuge tubes and pipettes used were coated with silicone (Siliclad, Clay Adams) to prevent the embryonic cells from sticking to the glassware.

The numbers of blastomeres and cells in mitosis of individual blastocysts were determined through the grid installed in the ocular pieces of the microscope. The total cell number was calculated and the mitotic index was expressed as a percentage of cells in mitosis over the total number of embryonic and trophoblast cells on the slide. Depending upon the size of blastocysts, the dilution of the cell suspension was adjusted. The degree of dispersion of the blastomeres by the technique was satisfactory (Pl. 1, Fig. 1). Good separation of the cells was obtained and no problems were encountered. As many as nineteen blastocysts could be obtained from a single rabbit by the ovulation regimen described. The ovulation rate observed in our regimen was 23.8 which was increased twofold over that reported with a single injection of $60 \mathrm{i} . \mathrm{u}$. HCG (Martin \& Shaver, $1972)$. In total, $80.2 \%(134 / 167)$ of the ova ovulated were observed as blastocysts in recovery media (Pl. 1, Fig. 2). This recovery rate ranged from $72.5 \%$ with 5-day blastocysts to $87 \cdot 3 \%$ with 6-day blastocysts (Table 1). A higher percentage of blastocysts was recovered intact from 4- and 5-day pregnant does $(100 \%$ and $86.2 \%$, respectively) than from 6-day pregnant does $(36.2 \%)$ 
PLATE I

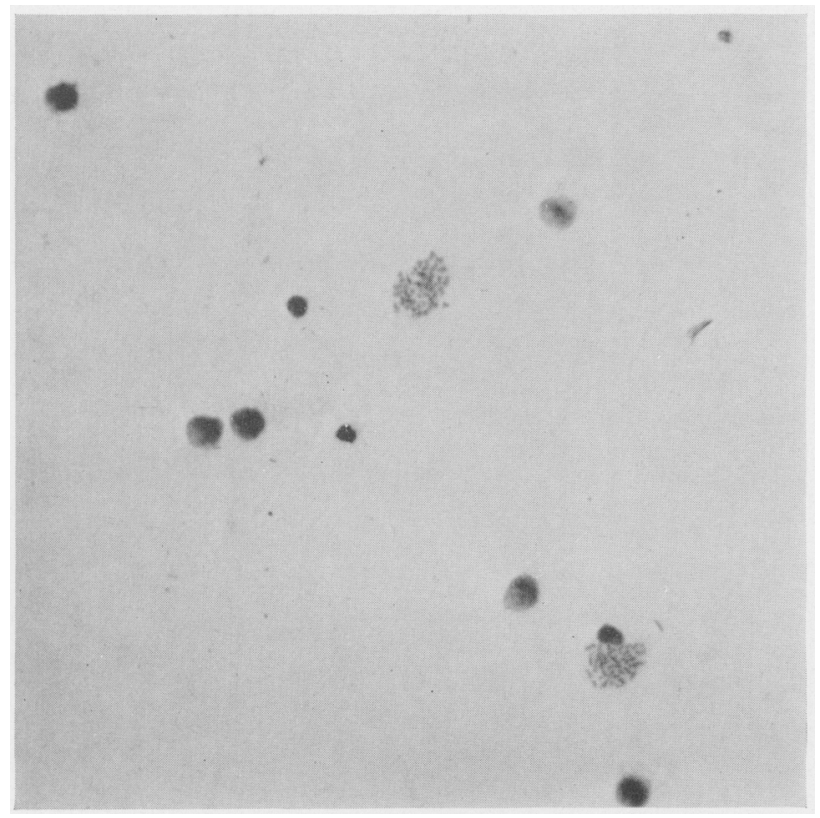

Fig. 1. Dispersion of the blastomeres on glass slides after treatment of a rabbit blastocyst.

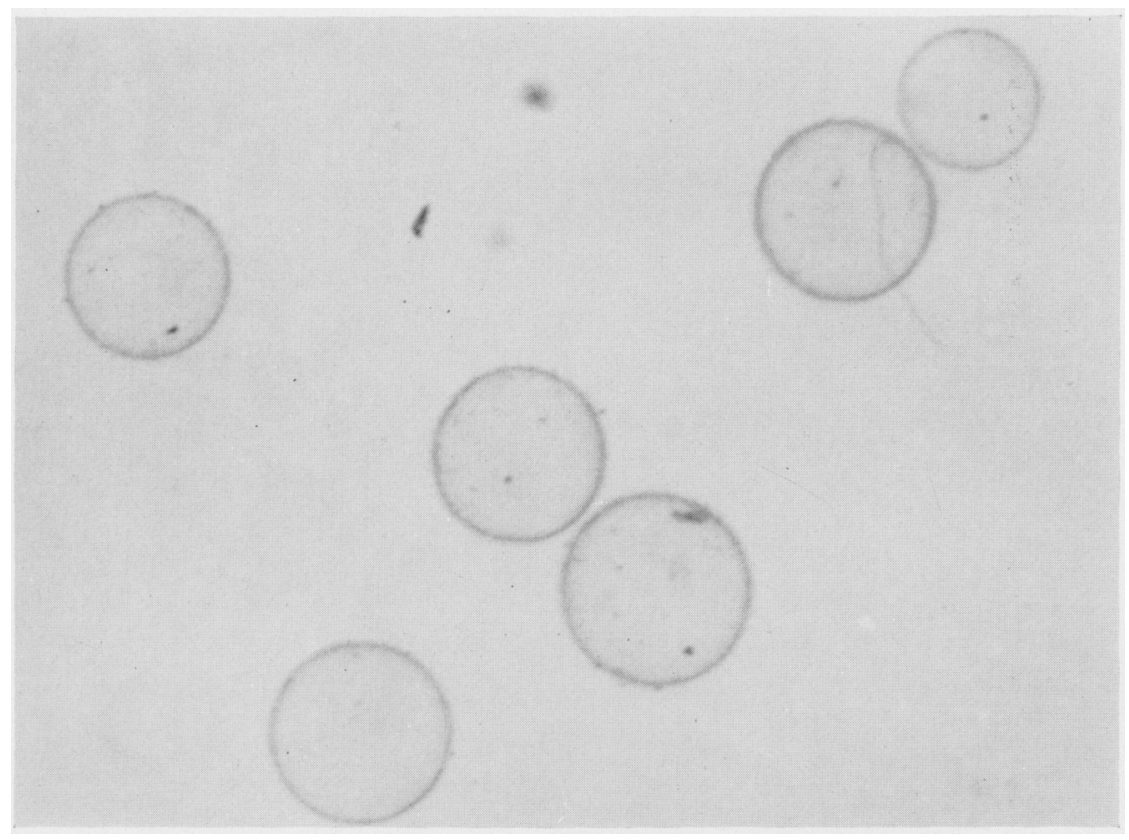

Fig. 2. Four-day, 16-hr-old blastocysts recovered from a rabbit uterus.

(Facing p. 370) 


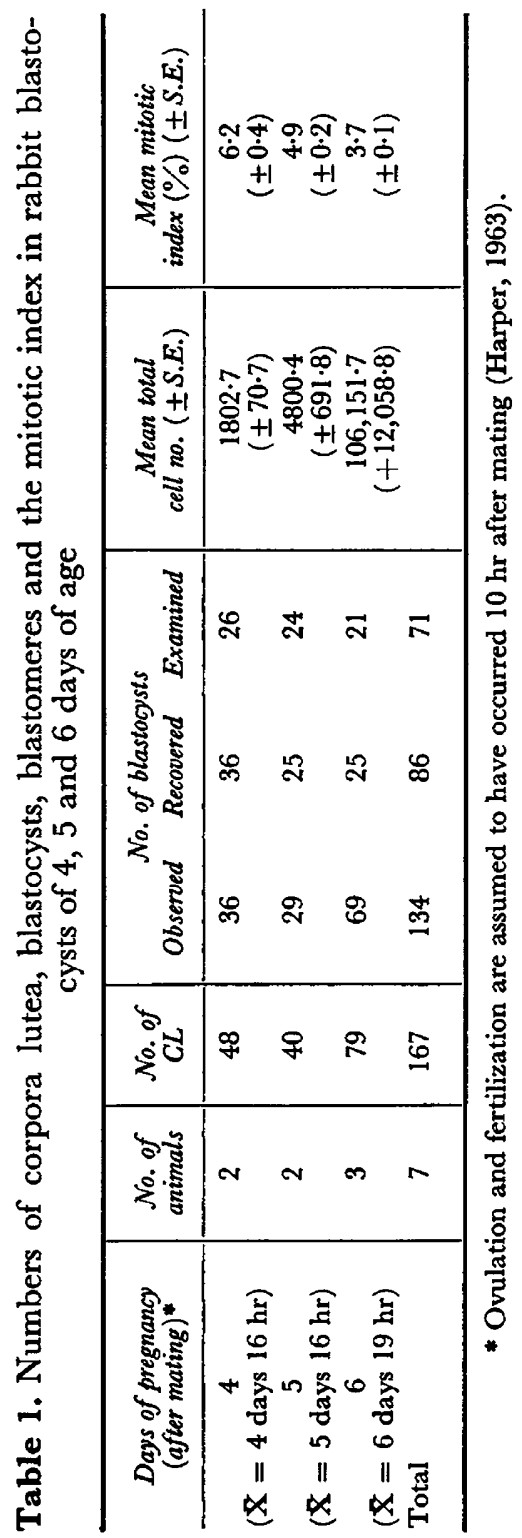


because of some early implantation occurring with those embryos recovered 6 days and $19 \mathrm{hr}$ after mating. This value represents blastocysts 6 days and $9 \mathrm{hr}$ after ovulation and fertilization.

The percentage of blastocysts observed $(82.6 \%)$ is comparable to those reported by Martin \& Shaver (1972) of $82.6 \%$ and Widmeyer \& Shaver (1972) of $86.9 \%$.

The numbers of blastomeres observed in each of the treatments are indicated in Table 1. When plotted on a semi-logarithmic scale, the increase in cell numbers is correlated linearly with the advancing stages of development during the time period studied.

The decrease in mitotic index from Day 4 to Day 6 probably indicates the more rapid growth of trophoblastic cells for implantation compared to embryonic cells. This decrease is in agreement with the report of Hansen-Melander \& Melander (1971).

Recent literature (Hansen-Melander \& Melander, 1971; Widmeyer \& Shaver, 1972) has indicated that small rabbit blastocysts (based on age) have a higher incidence of cytogenetic aberrations than normally developing conceptuses. In the early stage of pregnancy, especially the critical period when the free-floating blastocyst is exposed to the uterine environment factors, it is impossible to observe macromorphological aberrations other than the size of the blastocyst. Conceivably, the total cell number of an individual blastocyst before implantation is a more precise measure of developmental normality (at a given age) than is measurement of blastocyst size. The experimental importance of counting the total cell content in early embryos has been recognized but there have been few reports on a technique that allows estimation of this parameter. Using the method reported here, it is possible to calculate the total cell numbers in blastocysts at early ages. In addition, many metaphase plates are subsequently available for further chromosomal analysis. Thus, the size, total cell number, mitotic index and chromosomal analysis can be performed simultaneously from individual preimplantation blastocysts.

This project was supported by USPHS Grant No. 5-PO6-RR 00366-04, NIH Contract No. 70-2061, and NIH Research Career Development Award No. 1-K4-HD35, 306-01.

\section{REFERENGES}

GARR, D. H. (1965) Chromosome studies on spontaneous abortion. Obstet. Gynec., N.Y. 26, 308.

Falconer, D. S. (1960) The genetics of litter size in mice. 7. cell. comp. Physiol. 57, Suppl. 1, 153.

FoRD, E. H. R. \& Woollam, D. H. M. (1963) A colchicine, hypotonic citrate, air-drying sequence for foetal mammalian chromosomes. Stain Technol. 38, 271.

Geneva Conference (1966) Standardization of procedures for chromosome studies in abortion. Bull. Wld Hlth Org. 34, 765.

Hansen-Melander, E. \& Melander, Y. (1971) A case of spontaneous haploidy and notes on triploiddiploid mosaics in rabbit embryos. Hereditas, 67, 83.

HARPER, M. J. K. (1963) Ovulation in the rabbit: The time of follicular rupture and expulsion of the eggs, in relation to injection of luteinizing hormone. F. Endocr. 26, 307.

Ikeughi, T., Sasaki, M., Kohno, S., Hayata, I. \& Fujimoto, S. (1972) Chromosome studies on spontaneous and threatened abortions. Fap. F. Human Genet. 16, 191.

Kinsey, J. D. (1967) X-chromosome replication in early rabbit embryos. Genetics, Princeton, 55, 337. 
LUBs, H. A. \& RUDdLE, F. H. (1970) Chromosomal abnormalities in the human population: estimation of rates based on New Haven newborn study. Science, N.Y. 169, 495.

Makino, S., Ikeughi, T., Sasaki, M., Muramoto, J., Shimba, H., Fujmoto, S. \& Matsuda, S. (1967) A preliminary study of the chromosomes in spontaneous abortions. Proc. Fapan Acad. 43, 552.

MARTtN, P. A. \& Shaver, E. L. (1972) Sperm aging in utero and chromosomal anomalies in rabbit blastocysts. Devl Biol. 28, 480.

Ohzu, E. \& Makino, S. (1964) Some abnormalities produced by low-dose X-irradiations in early mouse embryos. Proc. Japan Acad. 40, 670.

SHAVER, E. L. \& GARR, D. H. (1967) Chromosome abnormalities in rabbit blastocysts following delayed fertilization. 7. Reprod. Fert. 14, 415.

WIDMEYER, M. A. \& ShaVeR, E. L. (1972) Estrogen, progesterone and chromosome abnormalities in rabbit blastocysts. Teratology, 6, 207. 